\section{TACKLING OCCUPATIONAL DISEASES IN DEVELOPING COUNTRIES: BUILDING CAPACITIES FOR EARLY DIAGNOSIS AND PREVENTION}

${ }^{1}$ Diana Gagliardi*, ${ }^{2}$ Shyam Pingle, ${ }^{2}$ Dileep Andhare. ${ }^{1}$ Italian Workers Compensation Authority (INAIL), Rome, Italy; ${ }^{2}$ Indian Institute of Public Health Gandhinagar, India

10.1136/oemed-2018-ICOHabstracts.870

Aim of special session To increase capacities to find and use practical solutions for early diagnosis and prevention of occupational diseases in day-to-day activity.

Dr. Kazutaka Kogi ${ }^{1}$, Dr. Gert van der Laan ${ }^{2}$, Ms. Suvi Lehtinen $^{3}$, Dr. Shyam Pingle ${ }^{4}$, Prof. Katja Radon ${ }^{5}$

${ }^{1}$ Ohara Memorial Institute for Science of Labour, Japan

${ }^{2}$ Foundation for Learning and Developing Occupational Health (LDOH), The Netherlands; Free University Medical Centre (VUmc), The Netherlands, International Centre for Rural Health, University of Milan, Italy

${ }^{3} \mathrm{MSc}$, Tampere, Finland

${ }^{4}$ Indian Institute of Public Health Gandhinagar, India

${ }^{5}$ Center for International Health LMU @ Institute and Clinic for Occupational, Social and Environmental Medicine, University Hospital, LMU Munich, Germany

\section{$1642 \mathrm{a}$ BUILDING PREVENTION-ORIENTED TEAM SUPPORT FOR GOOD OCCUPATIONAL HEALTH PRACTICES IN DEVELOPING COUNTRIES}

K Kogi, Y Sano. Ohara Memorial Institute for Science of Labour, Japan

\subsection{6/oemed-2018-ICOHabstracts.871}

Introduction In globalising economies, occupational health teams increasingly focus on locally adjusted support functions known as basic occupational health services. Networked collaboration in Asian countries indicate the importance of facilitating primary prevention of work-related risks through participatory steps leading to multifaceted workplace environment improvements. It is useful to know practical ways for developing countries to facilitate implementation of these improvements through locally adjusted risk management procedures.

Methods Recent experiences of occupational health teams within our Asian network for promoting participatory workplace improvement programs are examined. The reviewed programs aim at improving workplace environment in small enterprises, construction sites, agriculture and health care work. To know commonly effective procedures, we focus on solution-oriented procedures of addressing multifaceted risks usually identified in developing countries.

Results In the reviewed participatory programs, concrete results are usually obtained when the programs emphasise feasible low-cost improvements reflecting broad-ranging local good practices. This good-practice approach is effective when occupational health support teams focus on multifaceted improvements having real impacts on primary prevention of work-related risks. Typically, these improvements have a broad scope covering work methods, physical environment and teamwork arrangements. As means of facilitating the planning of risk-reducing improvements, broadly compiled good practices and 'action checklists' listing corresponding low-cost improvements have proven useful. Intervention studies on applying these participatory methods indicate actual reduction of multiple risks. The simplified solution-oriented procedures relying on group work of workers about feasible actions thus represent the core function of occupational health teams in facilitating primary prevention of work-related health risks.

Conclusions The solution-oriented support of occupational health teams directly aimed at locally feasible preventive measures is found essential, rather than detailed analysis of risk factors. Simplified participatory procedures are confirmed useful in facilitating primary prevention of multifaceted health hazards at workplaces in developing countries.

\section{2b EDUCATION AND TRAINING IN RECOGNITION, SURVEILLANCE AND PREVENTION OF OCCUPATIONAL DISEASES}

${ }^{1,2,3} \mathrm{G}$ van der Laan*, 1,2,4,5 F van Dijk. ${ }^{1}$ Foundation for Learning and Developing Occupational Health (LDOH), The Netherlands; ${ }^{2}$ Amsterdam Free University Medical Centre (VUmc), The Netherlands; ${ }^{3}$ International Centre for Rural Health, University of Milano, Italy; ${ }^{4}$ Coronel Institute, Academic Medical Centre Amsterdam, The Netherlands; ${ }^{5}$ Arbeits- und Umweltsepidemiologie and Net Teaching, Ludwich-Maximilians-Universität, München, Germany

\subsection{6/oemed-2018-ICOHabstracts.872}

Introduction There is a huge global need for good education, training and information on Occupational Safety and Health. Especially for tracing and prevention of occupational diseases. Internet can accelerate the process and coverage of education and training. In this session experiences in international projects will be shared.

Methods A range of activities in this field will be presented, especially from LDOH (www.ldoh.net):

- Development of online, blended and other materials for information and education, training courses on recognition, health surveillance, diagnosis, therapy and prevention of work-related diseases.

- Good practices like international summer school activities and Question and Answer facilities.

- New efforts involving primary or community health care as the foundation for basic occupational health care: Turkey, Thailand, Brazil, Vietnam, Iran, parts in China, new efforts in India, Bangladesh, South Africa.

Results and discussion

- Education and training in OHS is not a standalone activity. It should be programmatic and on many different levels, involving everyone who can be involved: vocational schools, using participatory approaches empowering communities and even including churches and private companies.

- Importance of OSH infrastructure (sector-wise, regional or national programs; involvement of Labour Inspection and Social Security Organisations), multidisciplinary collaboration and outreach-activities towards the entire global working population: all formal and informal workers with special attention for vulnerable groups (women, children, migrants, elderly): Universal Health Coverage (WHO).

- A more active role of International bodies? 


\section{C BUILDING CAPACITIES ON OSH IN DEVELOPING COUNTRIES: EXPERIENCES FROM FINLAND}

${ }^{1} S$ Lehtinen*, ${ }^{2}$ J Rantanen. ${ }^{1} \mathrm{MSC}$ (Econ.), Tampere, Finland; ${ }^{2}$ Helsinki University, Department of Public Health/Occupational Health, Helsinki, Finland

\subsection{6/oemed-2018-ICOHabstracts.873}

Introduction The socio-economic development of any country is dependent on the health, safety and well-being of its working population. In its development collaboration projects over the years, Finland has prioritised the improvement of working conditions and thereby the prevention of occupational accidents and diseases. Occupational health and safety collaboration has taken place with East Africa in particular, but also with South-East Asian countries.

Method Collaboration began as the provision of training for $\mathrm{OSH}$ experts, and later evolved into either country-targeted or regional programmes for developing the $\mathrm{OSH}$ infrastructures of the countries. These programmes included the capacity building of the actors involved. The practical collaboration with East Africa was realised together with the OSH Inspectorates, and the Institutes of Occupational Health in the countries, in which these were available. The financial support of the Finnish Ministry for Foreign Affairs made it possible to run the programmes.

Results In 1973-2009, collaboration grew from individual training courses for OSH experts in Zambia, Tanzania and later in Kenya, to more comprehensive projects that covered legislation development, policy and strategy planning, and support for practice-oriented research, training, information dissemination, and the provision of services. In the 1980s, the ILO-run Strengthening of Factories Inspectorates projects introduced a wider approach to OSH activities. At the end of the 1980s an East African Regional OSH programme was carried out with follow-up symposia in 1992, 1995 and 1998. Later in 2008-2009, a regional follow-up programme on OSH was conducted in East Africa. Many of the trainees of the time were or are now in key senior positions in occupational health and safety administration or other relevant organisations, including enterprises.

Discussion Among the most important features of collaboration and the lessons learnt during this are the comprehensive content of collaboration; maximising the use of networking, internationally, nationally and locally; and ensuring the continuity of the activities. This means that a committed staff is essential. The long-term development impact of expert training and training of future $\mathrm{OH}-\mathrm{OSH}$ leaders was deemed highly positive.

\section{2d CAPACITY BUILDING IN OSH: A VIEW FROM THE DEVELOPING COUNTRY}

${ }^{1} \mathrm{~S}$ Pingle ${ }^{*},{ }^{2} \mathrm{R}$ Parekh, ${ }^{1} \mathrm{D}$ Mavalankar. ${ }^{1}$ Indian Institute of Public Health Gandhinagar, India; ${ }^{2}$ Occupational Health Consultant, Mumbai, India

\subsection{6/oemed-2018-ICOHabstracts.874}

Access to specialised occupational health services is low across the world. However, the problem is very acute in developing countries due to various factors. Equitable health system cannot be achieved unless the lack of basic occupational health facilities for all the working population are addressed. India is an important and major developing country and represents the challenges in the developing countries to a great extent.

The most important $\mathrm{OSH}$ needs in developing countries such as India are:

1. legislation to extend $\mathrm{OSH}$ coverage to all sectors of working life including the unorganised sector,

2. spreading the awareness about OSH,

3. development of OSH infrastructure and OSH professionals.

4. Integration of occupational health with primary health care.

To address the increasing need of occupational health experts, capacity building is needed on a massive scale. The status of occupational health capacity in India reviewed from the available data and literature indicates huge gaps in the requirement and available capacity. The capacity established by the government has been grossly inadequate. Further, currently the services are aimed at organised sector and the huge need in unorganised sector is not being addressed.

Various nongovernmental international and national organisations have stepped in and have initiated various sensitisation, awareness and training programs with support from donors. Some of these programs have supported training of few experts from developing countries including India.

A case study of occupational health training and sensitisation of health care providers at primary level will be discussed. It is an initiative by Indian Association of Occupational Health which is a nongovernmental voluntary professional organisation of $\mathrm{OH}$ experts. Two of the international programs will also be discussed.

This presentation will review some of these initiatives and their outcome, the challenges faced and way forward. It will also discuss the potential role of expert associations.

\section{2e PROJECT-BASED TRAINING AS A TOOL TO TACKLE OCCUPATIONAL HEALTH CHALLENGES IN DEVELOPING COUNTRIES}

${ }^{1,2} \mathrm{~K}$ Radon ${ }^{*},{ }^{1,2} \mathrm{~L}$ Kurtz, ${ }^{1,2} \mathrm{D}$ Carvalho, ${ }^{1,2} \mathrm{~V}$ Encina, ${ }^{1,2} \mathrm{~F}$ van Dijk, ${ }^{1,2} \mathrm{C}$ Meneses, 1,2MA Garrido, 1,2MF Bauleo, 1,2 L Briceño, ${ }^{1,2} \mathrm{R}$ Herrera, ${ }^{1,2} \mathrm{M}$ Parra. ${ }^{1}$ Center for International Health LMU @ Institute and Clinic for Occupational, Social and Environmental Medicine, University Hospital, LMU Munich, Germany; ${ }^{2}$ Supported by German Academic Exchange Service, DAAD, via its Exceed program funded by the German Federal Ministry for Economic Cooperation and Development

\subsection{6/oemed-2018-ICOHabstracts.875}

Introduction To know the prevalence of exposures and diseases at workplaces is crucial for the development of intervention strategies and healthcare planning. However, in many low and middle-income countries (LMIC) research is no priority. One reason is a lack of experts able to carry out sound epidemiological research at workplaces. One way of preparing such experts is through project-based training. We therefore implemented a project as training method in our blended learning Master in International Occupational Safety and Health $(\mathrm{OSH})$.

Methods Students start by identifying their research interest based on existing worker's health problems. They develop a study protocol to assess working conditions and health at a self-selected workplace. After ethics approval, they carry out the project during the 2 nd term of the program. In term 3 , they learn to analyse and interpret data and develop a teaching intervention. In the final term, students write the master 